\section{JNK inhibitors: is there a future?}

\section{Jonas Cicenas}

MAP Kinase Resource and Institute of Animal Pathology, Bern, Switzerland; Vetsuisse Faculty, University of Bern and Proteomics Centre, Bern, Switzerland; Institute of Biochemistry, Vilnius University, Lithuania

\section{Abstract}

JNK is a subfamily of MAP kinases that hat regulates a range of biological processes implicated in response to stress, such as cytokines, ultraviolet irradiation, heat shock, and osmotic shock as well as growth factors like PDGF, EGF, FGF, etc. They were originally identified as kinases that bind and phosphorylate JUN on S63 and Se73 within its transcriptional activation domain. The deregulation of these kinases is shown to be involved in human diseases, such as cancer, immune diseases and neurodegenerative disorders. The realization of the therapeutic potential of the inhibition of JNKs led to a thorough search for small-molecule inhibitors first for research purposes, but later also for therapeutic applications. Here, we discuss some of the most well-known JNK inhibitors and their use in basic research or clinical science.

\section{Introduction}

Protein kinases are a large family of enzymes, which catalyze protein phosphorylation. The phosphorylation of proteins results in a change in localization of protein and/or their function such as interaction with other proteins, affinity or enzymatic activity. The human genome contains more than 510 protein kinase genes. Protein phosphorylation plays a crucial role in the regulation of many cellular functions such as proliferation, differentiation, migration and apoptosis. Because of that, deregulation of kinase activity can result in outstanding alterations in these processes. For example, deregulated kinases are frequently found to be oncogenic and can be essential for the survival of cancer cells. ${ }^{1}$ Moreover, the phosphorylation of some proteins, such as ErbB2, ${ }^{2-4}$ EGFR, ${ }^{3,5}$ Erk, ${ }^{6-8}$ SchA, ${ }^{9}$ Akt 10,11 and many more, is associated with prognosis in a number of human cancers.

c-Jun N-terminal kinases (JNKs) are members of subfamily of MAP kinase family of serine/threonine kinases which are found in both unicellular organisms such as yeast and multicellular organisms such as plants, fungi, and vertebrates. There are three different alternatively spliced genes MAPK8 (JNK1), MAPK9 (JNK2), and MAPK10 (JNK3) that produce ten different isoforms. JNK1 and JNK2 are ubiquitously expressed but JNK3 is expressed primarily in the nervous system. ${ }^{12-15}$ JNKs are activated by phosphorylation in the activation loop at residues Thr183/Tyr185 (JNK1, JNK2) or pThr-221 and pTyr-223 (JNK3) by the MAP2Ks: MAP2K4 (MKK4), MAP2K5 (MKK5) and MAP2K7 (MKK7), and are dephosphorylated and thus deactivated by MAP kinase phosphatases including DUSP1 (MKP1) and DUSP10 (MKP5). Signaling through the JNKpathway is organized through binding to scaffold proteins such as MAPK8IP1 (JIP1),16 MAPK8IP2 (JIP2), MAPK8IP3 (JIP3), SPAG9 (JIP4) ${ }^{17}$ or WDR62,18 which assemble signaling complexes containing MAP3K, MAP2K and MAPKs in addition to JNK-phosphorylated transcription factors such as JUN, ATF2 and ELK1.

JNKs are play a central role in the inflammatory signaling system, and thus it is not unexpected that deactivation of JNK signaling is very common in a number of diseases, such as cancers, inflammatory, autoimmune and neurodegenerative diseases. There's plenty evidence showing that JNKs could be considered as therapeutic targets in Parkinson's and Alzheimer's disease, 19,20 obesity and insulin resistance, ${ }^{21,22}$ rheumatoid arthritis, ${ }^{23}$ asthma, ${ }^{24-26}$ vascular disease and atherosclerosis. ${ }^{27}$

The importance of JNKs in many biological processes as well as pathologies led to a serious pursuit for small-molecule inhibitors, which resulted in various small molecules such as aminopyrazoles, aminopyridines, aminopyrimidines, indazoles, pyridine carboxamides, benzothien-2-ylamides and benzothiazol-2-yl acetonitriles to be reported as JNK inhibitors. ${ }^{28}$ Here we will discuss most interesting and successful of those.

\section{JNK inhibitors}

AS601245 is a potent and cell permeable ATP competitive JNK inhibitor. $\mathrm{IC}_{50}$ : JNK1 = $150 \mathrm{nM}, \mathrm{JNK} 2=220 \mathrm{nM}$, JNK3 $=70 \mathrm{nM}$ (Figure 1). Displays anti-inflammatory properties as shown in an experimental mouse model of rheumatoid arthritis ${ }^{29}$ and has been shown to reduce TNF- plasma levels induced by LPS in mice. ${ }^{30,31}$ It has also been shown to provide significant protection against the loss of hippocampal CA1 neurons in a gerbil model of transient global ischemia, suggesting that it may be a pertinent approach in the therapy of ischemic insults, ${ }^{32}$ it also reduced damage to
Correspondence: Jonas Cicenas, MAP Kinase Resource, Melchiorstrasse 9, CH-3027, Bern, Switzerland.

E-mail: j.cicenas@mapkinases.eu

Key words: JNK inhibitors; editorial.

Conflict of interest: the author reports no conflict of interest.

Received for publication: 20 December 2015. Accepted for publication: 21 December 2015.

This work is licensed under a Creative Commons Attribution NonCommercial 3.0 License (CC BYNC 3.0).

(C)Copyright J. Cicenas, 2015

Licensee PAGEPress, Italy

MAP Kinase 2015; 4:5700

doi:10.4081/mk.2015.5700

neurites and decreased astrogliosis in a similar study. 33 Likewise, this inhibitor rescued neuronal apoptosis in the developing rat brain after hypoxia-ischemia. ${ }^{34}$ AS601245 also decreased cardiomyocyte apoptosis and infarct size after myocardial ischemia and reperfusion in rat model of myocardial ischemia/reperfusion. ${ }^{35}$

Interesting findings have been obtained using AS601245 as an antiviral agent. AS601245 as well as SP600125 inhibited cellular entry and replication of hepatitis $\mathrm{C}$ virus. ${ }^{36}$ In addition, the application of SP600125 and AS601245 reduced influenza A virus (H7N7 and H1N1v) amplification by suppressing viral protein and RNA synthesis. ${ }^{37}$ AS601245 was also found to be a potent inhibitor of HIV-1 reactivation in latently infected primary $\mathrm{T}$ cells and T cell lines. ${ }^{38}$

Probably the most interesting are the findings of AS601245 as an anticancer agent. AS601245 decreased cell adhesion and migration via decrease in the fibrinogen release in human colon cancer cells. ${ }^{39}$ It has also affected the proliferation of colon cancer cell lines. ${ }^{40}$ AS601245 also led T-cell acute lymphoblastic leukemia cells to cell cycle arrest and apoptosis and increased sensitivity to Fas-mediated apoptosis $^{41}$ and sensitized promonocytic leukemia cells to arsenic trioxide-induced apoptosis.42

AS602801 (Bentamapimod) is a selective JNK inhibitor that has been found to block Tcell proliferation and induce apoptosis. $\mathrm{IC}_{50}$ : $\mathrm{JNK} 1=80 \mathrm{nM}, \mathrm{JNK} 2=90 \mathrm{nM}$, JNK3 $=230 \mathrm{nM}$ (Figure 1). This inhibitor blocked T-lymphocyte proliferation and induced apoptosis in relapsing-remitting multiple sclerosis patients. ${ }^{43}$ In addition, it has been shown to induce the regression of endometriotic lesions in human endometrial organ cultures, nude 
mice xenograft as well as rat disease models. ${ }^{44}$

$A E G 3482$ is a JNK inhibitor with an $\mathrm{IC}_{50}=20$ $\mu \mathrm{M}$ (Figure 1). The action is not direct, since it binds Hsp90 and facilitates HSF1 release, induces expression of $\mathrm{Hsp} 70$, which in turn blocks JNK activation. It also reduces apoptosis of neonatal sympathetic neurons after NGF withdrawal. 45 It was also shown to decrease neuron specific toxicity of oligomeric amyloid $\beta .46$

BI $78 D 3$ is a JNK inhibitor with an $\mathrm{IC}_{50}=$ $280 \mathrm{nM}$. It displays $>100$ fold selectivity over p38 kinases and no activity towards mTOR and PI-3K (Figure 1). BI 78D3 acts via inhibition of JIP1-JNK binding. It has also been shown to restores insulin sensitivity in mouse disease models of type 2 diabetes. ${ }^{47} \mathrm{BI}-78 \mathrm{D} 3$ as well as SP600125 reduced phenylephrine- and noradrenaline-induced contractions of human prostate smooth muscle. 48 Interestingly, BI78D3 pretreatment sensitized osteosarcoma cells (but not normal osteoblasts) to doxorubicin-induced apoptosis, ${ }^{49}$ which gives some ground for thoughts regarding the future combination treatment.

$C C-401$ is a specific inhibitor of JNK with $\mathrm{IC}_{50}=25-50 \mathrm{nM}$. It is a second generation ATPcompetitive inhibitor selective against JNK over other kinases such as p38, ERK, IKK2 and ZAP70 (Figure 2). It was shown to significantly inhibit renal fibrosis and tubular cell apoptosis, thus suggesting JNK pathway as a potential therapeutic target in progressive kidney disease.$^{50}$ In addition, CC-401 blocked reduced proteinuria in rat experimental anti-GBM glomerulonephritis ${ }^{51}$ and crescent formation, in a rat model of severe crescentic anti-GBM glomerulonephritis.52 CC-401 was also shown to decrease hepatic necrosis and apoptosis after orthotopic liver transplantation in rats ${ }^{53}$ and hepatic ischemia reperfusion injury. ${ }^{54,55}$ CC-401 in combination with oxaliplatin showed synergism in colon cancer cell lines HT29 and SW620 both in vitro and in mouse xenografts. ${ }^{56}$ CC-401 as well as SP600125 efficiently inhibited human cytomegalovirus replication in cultured human fibroblast. 57

SP600125 is a potent, selective and reversible inhibitor of JNK enzymes, with $\mathrm{IC}_{50}$ : JNK1, JNK2 = 40 nM JNK3 = 90 nM. Inhibition is over 300 -fold more selective for JNK as compared to ERK and p38 MAP kinases (Figure 2). It is the most widely used JNK inhibitor in basic and clinical research, with several hundred papers published. One of the main clinical aspects of SP600125 is the neuroprotection. It was shown to protect dopaminergic neurons form the apoptosis in the 1-methyl-4-phenyl1,2,3,6-tetrahydropyridine model of Parkinson's disease ${ }^{58}$ protect a transient brain ischemia/reperfusion-induced neuronal death in rat hippocampal CAlneurons, ${ }^{59,60}$ protect cerebellar granule cells against potassium deprivation-induced apoptosis, ${ }^{61}$ decrease streptozotocin induced neurocognitive deficit and

oxidative stress in rats, ${ }^{62}$ prevent the disruption of blood-brain barrier induced by methamphetamine $^{63}$ and diminish neuronal cell death in experimental cerebral malaria in mice. ${ }^{64}$ Worth mentioning is anticancer activity of SP600125 as well. It was shown to induce cell death selectively in undifferentiated thyroid cancer cell lines, ${ }^{65}$ sensitize the multidrugresistant KBV20C human oral squamous carcinoma cell line, ${ }^{6} 6$ enhance TGF- -induced apoptosis of human cholangiocarcinoma cell line RBE, ${ }^{67}$ suppress glioblastoma cells, ${ }^{68}$ selectively kill p53-deficient human colon carcinoma cells in mouse xenograft model, 69 enhance dihydroartemisinin-induced apoptosis in human lung adenocarcinoma cells ${ }^{70}$ and reduce the viability of doxorubicin resistant stomach cancer cells. ${ }^{71}$ Inflammation is another area where SP600125 has been extensively studied. It was shown to have protective effects in an experimental model of cerulein-induced pancreatitis, ${ }^{72}$ diet-induced rat model of nonalcoholic steatohepatitis ${ }^{73}$ and mouse model of allergic airway inflammation ${ }^{74}$ and promote resolution of allergic airway inflammation in murine acute asthma model.75 In addition, SP600125 had protective effects of on renal ischemia-reperfusion injury in rats 76,77 and hepatic failure. ${ }^{78}$ It also had antiviral activities, as mentioned above as well as suppressed allograft rejection. ${ }^{79}$

SU 3327 is a selective inhibitor of JNK with $\mathrm{IC}_{50}=0.7 \mu \mathrm{M}$. As BI 78D3, SU 3327 also acts via inhibition of JIP1-JNK binding $\left(\mathrm{IC}_{50}=239\right.$

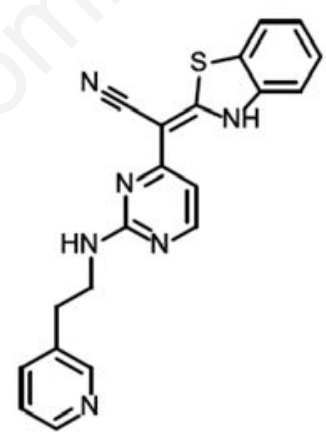

AS601245

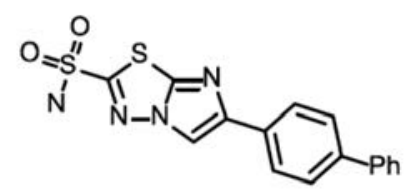

AEG 3482
nM) (Figure 2).80 Pre-treatment of human astrocytes with either SP600125 or SU 3327, and trauma-induced human astrocyte retraction in in vitro study. ${ }^{81}$ Inhibition of JNK by SU3327 was shown to aggravate the recovery of rat hearts after global ischemia. ${ }^{82}$ SU 3327 was also shown to reduced mitochondrial dysfunction and liver damage in acute liver injury mouse model. 83

\section{Tanzisertib (CC-930) and D- JNKI-1 (XG-102, AM-111) - First JNK inhibitors in clinical trials}

Tanzisertib (CC-930) is a potent, selective, and orally active JNK inhibitor, developed by Cellgene company, with $\mathrm{IC}_{50}$ : JNK1 $=0.06 \mu \mathrm{M}$, JNK2 $=0.007 \mu \mathrm{M}$ and JNK3 $=0.006 \mu \mathrm{M}$ and selective against MAP kinases ERK1 and p38 with $\mathrm{IC}_{50}$ of 0.48 and $3.4 \mu \mathrm{M}$ respectively. ${ }^{84}$ of a panel of 240 kinases, EGFR was the only nonMAP kinase showing $\mathrm{IC}_{50}$ of $0.38 \mu \mathrm{M}$ (Figure 2). CC-390 was also evaluated in several animal models. In acute rat LPS-induced inflammation model inhibited the production of TNF by $23 \%$ and $77 \%$ at 10 and $30 \mathrm{mg} / \mathrm{kg}$ oral dose respectively. In a mouse bleomycin-induced pulmonary fibrosis model it reduced Lung fibrosis scores by $18-32 \%$ in dose dependent manner (25-150 mg/kg CC-930 prior to admin-

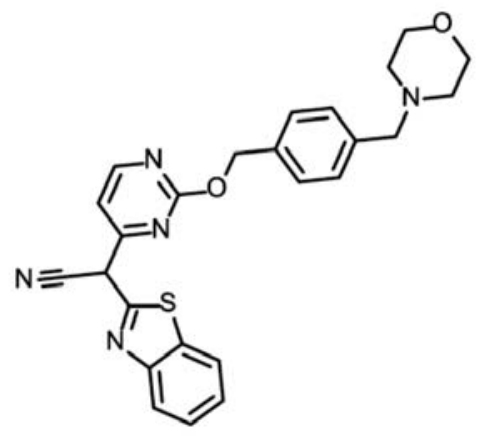

AS602801

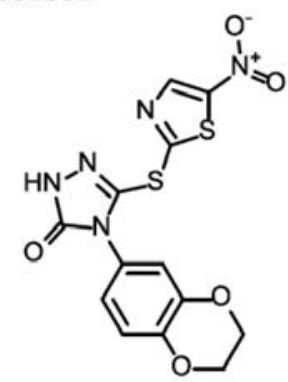

BI 78D3

Figure 1. AS601245, AS602801 (Bentamapimod), AEG 3482 and BI 78D3. 
istration of bleomycin). 85 Based on animal models and negative toxicity results, CC-930 was selected as a further development candidate for Phase I clinical trial. Results from Phase I trials in healthy male volunteers have indicated that CC-930 was well-tolerated and exposure was dose-proportional, therefore CC930 was advanced to Phase II clinical trial to characterize the safety, pharmacokinetics, and biological activity in patients with idiopathic pulmonary fibrosis. 86 Trial design was following: 4-week placebo-controlled double-blind treatment phase; CC-930 sequential escalation oral doses: $50 \mathrm{mg}$ QD, $100 \mathrm{mg}$ QD, $100 \mathrm{mg}$ BID; 52 -week open-label treatment extension plus 52-week follow-up phase. Preliminary results showed that he change in MMP-7 plasma levels significantly correlated with the change in lung function and there was a decrease in MMP-7 plasma level with increasing CC-930 dose and drug exposure. However, Tanzisertib clinical development has been discontinued due to unfavorable risk/benefit profile.

D-JNKI-1 (XG-102, AM-111) is one of the best known and most used peptide inhibitors of JNK [others being TI-JIP, TAT-TIJIP and LJNKI (XG-101)]. It is an inhibitory peptide derived from JIP and is blocking JNK-JIP interaction. D-JNKI-1 is the D aminoacid-containing retroinverso peptide, derived from the JIP JNK-binding domain sequence ${ }^{87}$ (Figure 3 ). A number of preclinical studies using this peptide inhibitor, resulted in clinical evaluations. In a model of hearing loss using organ cultures of neonatal mouse cochlea exposed to an aminoglycoside and cochleae of adult guinea pigs that were exposed to either an aminoglycoside or acoustic trauma, D-JNKI-1 protected against auditory hair cell death and resulting hearing loss. ${ }^{88}$ In addition, delayed phase of hearing loss caused by cochlear implant electrode insertion in guinea pigs can be prevented by D-JNKI-1 treatment of cochlea. ${ }^{89}$ In chinchilla model for permanent hearing loss from impulse noise trauma, this inhibitor also had a protective effect. ${ }^{90} \mathrm{D}$-JNKI-1 also reduced hearing loss in a guinea pig model of acute labyrinthitis. ${ }^{91}$ Based on these preclinical findings, a prospective randomized phase I/II study was initiated for the intratympanic treatment of acute acoustic trauma with D-JNKI-1.92 The signs of a therapeutic effect were seen in this study. Some adverse events were reported in $45 \%$ (5/11) of study participants; however none of them were serious or severe. Another double-blind, randomized, placebo-controlled phase II study for treatment of acute sensorineural hearing loss was initiated by Auris Medical. ${ }^{93}$ Single-dose intratympanic injection of D-JNKI-1 ( 0.4 or $2.0 \mathrm{mg} / \mathrm{mL})$ or placebo was used in 210 patients within $48 \mathrm{~h}$ after acute acoustic trauma or idiopathic sudden sensorineural hearing loss. $0.4 \mathrm{mg} / \mathrm{mL}$ showed statistically significant, clinically relevant, and persistent improvements in hearing compared with placebo; the drug was well tolerated. The same company is currently organizing two crucial phase III clinical trials in the treatment of idiopathic sudden sensorineural hearing loss: HEALOS (Europe/Asia, start Q4/2015) and ASSENT (USA, start Q2/2016). In both trials a single dose of D-JNKI-1 $0.4 \mathrm{mg} / \mathrm{mL}$ or 0.8 $\mathrm{mg} / \mathrm{mL}$ will be compared to placebo in patients<smiles></smiles><smiles></smiles>

suffering from acute severe to profound hearing loss within 72 hours from idiopathic sudden sensorineural hearing loss onset. ${ }^{94}$ In addition, a phase II trial in the treatment of surgery-induced hearing loss called REACH (USA; start Q3/2016) is being prepared.94 DJNKI-1 will be administered intraoperatively in patients with residual hearing who are undergoing cochlear implant surgery and who are at

Figure 2. CC-401, SP600125, SU 3327 and CC-930 (Tanzisertib).

A

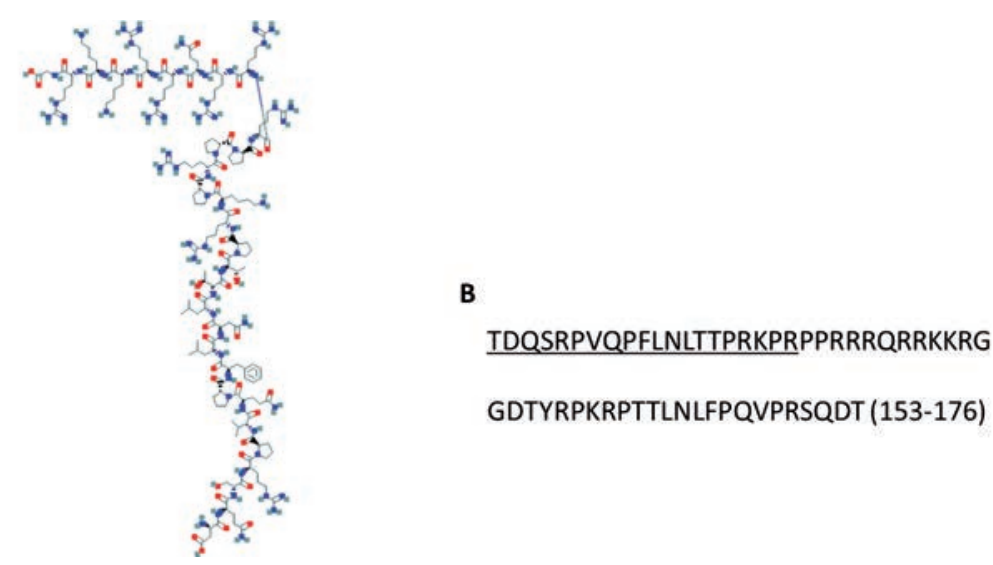

Figure 3. D-JNKI-1 (XG-102, AM-111). A) 2D structure of D-JNKI-1 peptide (copied from https://pubchem.ncbi.nlm.nih.gov/compound/72941992). B) D-JNKI-1 peptide amino acids: above - $\mathrm{D}$ aminoacid-containing retroinverso peptide, with underline amino acids, corresponding to JIP1 protein; under - the JIP1 JNK-binding domain sequence from which amino acids were derived. 
risk of losing residual hearing.

Similarly, the preclinical model, such as endotoxin-induced uveitis in rats, ${ }^{95}$ led to the indication of the phase I clinical trial in 20 patients with intraocular inflammation. ${ }^{96}$ Patients were assigned to 1 of the 4 dose escalating $(45,90,450$, or $900 \mu \mathrm{g}$ D-JNKI-1) groups of 5 patients each. Drug safe and well tolerated [17 non-serious adverse events, considered unrelated to the study treatment, were reported for 50\% (10/10 patients); adverse event incidence was not related to the drug dose], however further studies are required to evaluate its efficacy. Several other pathological conditions have been tested in preclinical animal models, such as cerebral ischemia, ${ }^{97-100}$ neuropathic pain,101 myocardial ischemia-reperfusion injury, 102 hepatic damage, 103,104 middle cerebral artery occlusion, 105 skin cancer, ${ }^{99}$ Alzheimer's disease, 106,107 non-alcoholic steatohepatitis, 108 colitis, 109 spinal cord injury110 and others, suggesting, that many more clinical trials are underway.

\section{Conclusions and Future Perspectives}

Regardless of significant developments in latest years in the development of JNK, many questions are yet unanswered. One of the main concerns is the JNK inhibitor specificity and suitable ways to control it. Another important question is whether the inhibitors selective for individual JNK isoforms are designable. On the other hand, knock-out and/or siRNA studies should help to establish whether isoform-specific inhibitors are at all desirable. So far, judging by phenotypes of JNK1, JNK2 and JNK3 knock-out mice, JNK isoform-selective inhibitors seem to be valuable, 111 however experiences with other kinases show, that in many cases inhibitors with broader selectivity sometimes are more beneficial than very specific ones. The sequence similarity between isoforms could also make it extremely difficult to achieve the specificity. Peptide inhibitors might be able to solve these problems. On the other hand, new approached, such like computer-assisted, 3D structure based approaches to generate new generations of kinase inhibitors 112 might solve a lot of problems as well. On the other hand, from the studies on other kinase, such as CDKs, ${ }^{113}$ it seems that combination therapies are more hopeful than immunotherapies, therefore chemotherapeutic or other agents should be evaluated in combination with JNK inhibitors. Other targeted drugs such as inhibitors of other kinases as well as other enzymes should also be evaluated in combination with JNK inhibition.

\section{References}

1. Hunter T, Cooper JA. Protein-tyrosine kinases. Annu Rev Biochem 1985;54:897930.

2. Cicenas J, Urban P, Küng W, et al. Phosphorylation of tyrosine 1248-ERBB2 measured by chemiluminescence-linked immunoassay is an independent predictor of poor prognosis in primary breast cancer patients. Eur J Cancer 2006;42: $636-45$.

3. Cicenas J. The potential role of EGFR/ErbB2 heterodimer in breast cancer. Exp Opin Ther Patents 2007;17:60716.

4. DiGiovanna MP, Stern DF, Edgerton SM, et al. Relationship of epidermal growth factor receptor expression to ErbB-2 signaling activity and prognosis in breast cancer patients. J Clin Oncol 2005;23:1152-60.

5. Kanematsu T, Yano S, Uehara $\mathrm{H}$, et al. Phosphorylation, but not overexpression, of epidermal growth factor receptor is associated with poor prognosis of nonsmall cell lung cancer patients. Oncol Res 2003;13:289-98.

6. Milde-Langosch K, Bamberger AM, Rieck G, et al. Expression and prognostic relevance of activated extracellular-regulated kinases (ERK1/2) in breast cancer. Br J Cancer 2005;92:2206-15.

7. Bergqvist J, Elmberger G, Ohd J, et al. Activated ERK1/2 and phosphorylated oestrogen receptor alpha are associated with improved breast cancer survival in women treated with tamoxifen. Eur J Cancer 2006;42:1104-12.

8. Svensson S, Jirström K, Rydén L, et al. ERK phosphorylation is linked to VEGFR2 expression and Ets-2 phosphorylation in breast cancer and is associated with tamoxifen treatment resistance and small tumors with good prognosis. Oncogene 2005;24:4370-9.

9. Cicenas J, Küng W, Eppenberger U, et al. Increased level of phosphorylated ShcA measured by chemiluminescence- linked immunoassay is a predictor of good prognosis in primary breast cancer expressing low levels of estrogen receptor. Cancers 2010;2:153-64.

10. Cicenas J, Urban P, Vuaroqueaux V, et al. Increased level of phosphorylated akt measured by chemiluminescence-linked immunosorbent assay is a predictor of poor prognosis in primary breast cancer overexpressing ErbB-2. Breast Cancer Re 2005;7:R394-R401.

11. Cicenas J. The potential role of Akt phosphorylation in human cancers. Int J Bio Markers 2008;23:1-9.
12. Dérijard B, Hibi M, Wu IH, et al. JNK1: a protein kinase stimulated by UV light and Ha-Ras that binds and phosphorylates the c-Jun activation domain. Cell 1994;76:1025-37.

13. Kallunki T, Su B, Tsigelny I, et al. JNK2 contains a specificity-determining region responsible for efficient c-Jun binding and phosphorylation. Genes Dev 1994; 8:2996-3007.

14. Sluss HK, Barrett T, Dérijard B, et al. Signal transduction by tumor necrosis factor mediated by JNK protein kinases. Mol Cell Biol 1994;14:8376-84.

15. Mohit AA, Martin JH, Miller CA. p493F12 kinase: a novel MAP kinase expressed in a subset of neurons in the human nervous system. Neuron 1995;14:67-78.

16. Whitmarsh AJ, Kuan CY, Kennedy NJ, et al. Requirement of the JIP1 scaffold protein for stress-induced JNK activation. Genes Dev 2001;15:2421-32.

17. Engström W, Ward A, Moorwood K. The role of scaffold proteins in JNK signalling. Cell Prolif 2010;43:56-66.

18. Hadad M, Aviram S, Darlyuk-Saadon I, et al. The association of the JNK scaffold protein, WDR62, with the mixed lineage kinase 3, MLK3. MAP Kinase 2015;4:12 17.

19. Hunot S, Vila M, Teismann P, et al. JNKmediated induction of cyclooxygenase 2 is required for neurodegeneration in a mouse model of Parkinson's disease. Proc Natl Acad Sci U S A 2004;101:665-70.

20. Mehan S, Meena H, Sharma D, et al. JNK: a stress-activated protein kinase therapeutic strategies and involvement in Alzheimer's and various neurodegenerative abnormalities. J Mol Neurosci 2011; 43:376-90.

21. Hirosumi J, Tuncman G, Chang L, et al. A central role for JNK in obesity and insulin resistance. Nature 2002;420:333-6.

22. Sabio G, Kennedy NJ, Cavanagh-Kyros J, et al. Role of muscle c-Jun NH2-terminal kinase 1 in obesity-induced insulin resistance. Mol Cell Biol 2010;30:106-15.

23. Han Z, Chang L, Yamanishi Y, et al. Joint damage and inflammation in c-Jun N-terminal kinase 2 knockout mice with passive murine collagen-induced arthritis. Arthritis Rheum 2002;46:818-23.

24. Pelaia G, Cuda G, Vatrella A, et al. Mitogen-activated protein kinases and asthma. J Cell Physiol 2005;202:642-53.

25. Blease K, Lewis A, Raymon HK. Emerging treatments for asthma. Exp Opin Emerg Drugs 2003;8:71-81.

26. Chialda L, Zhang $\mathrm{M}$, Brune $\mathrm{K}$, et al. Inhibitors of mitogen-activated protein kinases differentially regulate costimulated $\mathrm{T}$ cell cytokine production and mouse airway eosinophilia. Respir Res 


\section{5;15:6-36.}

27. Osto E, Matter CM, Kouroedov A, et al. cJun N-terminal kinase 2 deficiency protects against hypercholesterolemiainduced endothelial dysfunction and oxidative stress. Circulation 2008; 118:2073-80.

28. LoGrasso P, Kamenecka T. Inhibitors of cjun-N-terminal kinase (JNK). Mini Rev Med Chem 2008;8:755-66.

29. Gaillard P, Jeanclaude-Etter I, Ardissone $\mathrm{V}$, et al. Design and synthesis of the first generation of novel potent, selective, and in vivo active (benzothiazol-2-yl)acetonitrile inhibitors of the c-Jun N-terminal kinase. J Med Chem 2005;48:4596-607.

30. Wang LW, Chang YC, Chen SJ, et al. TNFR1-JNK signaling is the shared pathway of neuroinflammation and neurovascular damage after LPS-sensitized hypoxic-ischemic injury in the immature brain. J Neuroinflammation 2014;11:215.

31. Wang LW, Tu YF, Huang CC, et al. JNK signaling is the shared pathway linking neuroinflammation, blood-brain barrier disruption, and oligodendroglial apoptosis in the white matter injury of the immature brain. J Neuroinflammation 2012;9:175.

32. Carboni S, Hiver A, Szyndralewiez C, et al. AS601245 (1,3-benzothiazol-2-yl (2-[ [2(3-pyridinyl) ethyl] amino]-4 pyrimidinyl) acetonitrile): a c-Jun NH2-terminal protein kinase inhibitor with neuroprotective properties. J Pharmacol Exp Ther 2004;310:25-32.

33. Carboni S, Boschert U, Gaillard P, et al. AS601245, a c-Jun NH2-terminal kinase (JNK) inhibitor, reduces axon/dendrite damage and cognitive deficits after global cerebral ischaemia in gerbils. $\mathrm{Br} \mathrm{J}$ Pharmacol 2008;153:157-63.

34. Li D, Li X, Wu J, et al. Involvement of the JNK/FOXO3a/Bim Pathway in Neuronal Apoptosis after Hypoxic-Ischemic Brain Damage in Neonatal Rats. PLoS One 2015;10:e0132998.

35. Ferrandi C, Ballerio R, Gaillard P, et al. Inhibition of c-Jun $\mathrm{N}$-terminal kinase decreases cardiomyocyte apoptosis and infarct size after myocardial ischemia and reperfusion in anaesthetized rats. $\mathrm{Br}$ J Pharmacol 2004;142:953-60.

36. Kim S, Ishida H, Yamane $\mathrm{D}$, et al. Contrasting roles of mitogen-activated protein kinases in cellular entry and replication of hepatitis C virus: MKNK1 facilitates cell entry. J Virol 2013;87:4214-24.

37. Nacken W, Ehrhardt C, Ludwig S. Small molecule inhibitors of the c-Jun N-terminal kinase (JNK) possess antiviral activity against highly pathogenic avian and human pandemic influenza A viruses. Biol Chem 2012;393:525-34.

38. Wolschendorf F, Bosque A, Shishido T, et al. Kinase control prevents HIV-1 reactivation in spite of high levels of induced NF-KB activity. J Virol 2012;86:4548-58.

39. Cerbone A, Toaldo C, Minelli R, et al. Rosiglitazone and AS601245 decrease cell adhesion and migration through modulation of specific gene expression in human colon cancer cells. PLoS One 2012;7:e40149.

40. Cerbone A, Toaldo C, Pizzimenti S, et al. AS601245, an Anti-inflammatory JNK inhibitor, and clofibrate have a synergistic effect in inducing cell responses and in affecting the gene expression profile in CaCo-2 colon cancer cells. PPAR Res 2012;2012:269751.

41. Cui J, Wang Q, Wang J, et al. Basal c-Jun $\mathrm{NH} 2$-terminal protein kinase activity is essential for survival and proliferation of T-cell acute lymphoblastic leukemia cells. Mol Cancer Ther 2009;8:3214-22.

42. Ramos AM, Fernandez C, Amrán D, et al. Pharmacologic inhibitors of extracellular signal-regulated kinase (ERKs) and c-Jun $\mathrm{NH}(2)$-terminal kinase (JNK) decrease glutathione content and sensitize human promonocytic leukemia cells to arsenic trioxide-induced apoptosis. J Cell Physiol 2006;209:1006-15.

43. Ferrandi C, Richard F, Tavano P, et al. Characterization of immune cell subsets during the active phase of multiple sclerosis reveals disease and c-Jun $\mathrm{N}$-terminal kinase pathway biomarkers. Mult Scler 2011;17:43-56.

44. Palmer SS, Altan M, Denis D, et al. Bentamapimod (JNK Inhibitor AS602801) induces regression of endometriotic lesions in animal models. Reprod Sci 2016;23:11-23.

45. Salehi AH, Morris SJ, Ho WC, et al. AEG3482 is an antiapoptotic compound that inhibits Jun kinase activity and cell death through induced expression of heat shock protein 70. Chem Biol 2006;13:21323.

46. Ebenezer PJ, Weidner AM, LeVine H 3rd, et al. Neuron specific toxicity of oligomeric amyloid- $\beta$ : role for JUN-kinase and oxidative stress. J Alzheimers Dis 2010;22:839-48.

47. Stebbins JL, De SK, Machleidt T, et al. Identification of a new JNK inhibitor targeting the JNK-JIP interaction site. Proc Natl Acad Sci U S A 2008;105:16809-13.

48. Strittmatter F, Walther S, Gratzke C, et al. Inhibition of adrenergic human prostate smooth muscle contraction by the inhibitors of c-Jun N-terminal kinase, SP600125 and BI-78D3. Br J Pharmacol 2012;166:1926-35.

49. Posthumadeboer J, van Egmond PW, Helder MN, et al. Targeting JNK-interacting-protein-1 (JIP1) sensitises osteosar- coma to doxorubicin. Oncotarget 2012;3:1169-81.

50. Ma FY, Flanc RS, Tesch GH, et al. A pathogenic role for c-Jun amino-terminal kinase signaling in renal fibrosis and tubular cell apoptosis. J Am Soc Nephrol 2007;18:472-84.

51. Flanc RS, Ma FY, Tesch GH, et al. A pathogenic role for JNK signaling in experimental anti-GBM glomerulonephritis. Kidney Int 2007;72:698-708.

52. Ma FY, Flanc RS, Tesch GH, et al. Blockade of the c-Jun amino terminal kinase prevents crescent formation and halts established anti-GBM glomerulonephritis in the rat. Lab Invest 2009;89:470-84.

53. Uehara T, Xi Peng X, Bennett B, et al. cJun $\mathrm{N}$-terminal kinase mediates hepatic injury after rat liver transplantation. Transplantation 2004 Aug;78:324-32.

54. Uehara T, Bennett B, Sakata ST, et al. JNK mediates hepatic ischemia reperfusion injury. J Hepatol 2005;42:850-9.

55. Kanellis J, Ma FY, Kandane-Rathnayake $\mathrm{R}$, et al. JNK signalling in human and experimental renal ischaemia/reperfusion injury. Nephrol Dial Transplant 2010;25:2898-908.

56. Vasilevskaya IA, Selvakumaran M, Hierro LC, et al. Inhibition of JNK sensitizes hypoxic colon cancer cells to DNA-damaging agents. Clin Cancer Res 2015;21: 4143-52.

57. Zhang H, Niu X, Qian Z, et al. The c-Jun N-terminal kinase inhibitor SP600125 inhibits human cytomegalovirus replication. J Med Virol 2015;87:2135-44.

58. Wang W, Shi L, Xie Y, et al. SP600125, a new JNK inhibitor, protects dopaminergic neurons in the MPTP model of Parkinson's disease. Neurosci Res 2004;48: 195-202.

59. Guan $\mathrm{QH}$, Pei DS, Zhang QG, et al. The neuroprotective action of SP600125, a new inhibitor of JNK, on transient brain ischemia/reperfusion-induced neuronal death in rat hippocampal CA1 via nuclear and non-nuclear pathways. Brain Res 2005;1035:51-9.

60. Guan QH, Pei DS, Liu XM, et al. Neuroprotection against ischemic brain injury by SP600125 via suppressing the extrinsic and intrinsic pathways of apoptosis. Brain Res 2006;1092:36-46.

61. Yeste-Velasco M, Folch J, Casadesús G, et al. Neuroprotection by c-Jun NH2-terminal kinase inhibitor SP600125 against potassium deprivation-induced apoptosis involves the Akt pathway and inhibition of cell cycle reentry. Neuroscience 2009; 159:1135-47.

62. Sharma N, Deshmukh R, Bedi KL. SP600125, a competitive inhibitor of JNK attenuates streptozotocin induced neu- 
rocognitive deficit and oxidative stress in rats. Pharmacol Biochem Behav 2010;96: 386-94.

63. Urrutia A, Rubio-Araiz A, Gutierrez-Lopez MD, et al. A study on the effect of JNK inhibitor, SP600125, on the disruption of blood-brain barrier induced by methamphetamine. Neurobiol Dis 2013;50:49-58.

64. Anand SS, Maruthi M, Babu PP. The specific, reversible JNK inhibitor SP600125 improves survivability and attenuates neuronal cell death in experimental cerebral malaria (ECM). Parasitol Res 2013;112:1959-66.

65. Grassi ES, Vezzoli V, Negri I, et al. SP600125 has a remarkable anticancer potential against undifferentiated thyroid cancer through selective action on ROCK and p53 pathways. Oncotarget 2015 6:36383-99.

66. Kim JH, Chae M, Choi AR, et al. SP600125 overcomes antimitotic drug-resistance in cancer cells by increasing apoptosis with independence of P-gp inhibition. Eur J Pharmacol 2014;723:141-7.

67. Lin $\mathrm{Y}$, Zhang $\mathrm{B}$, Liang $\mathrm{H}$, et al. JNK inhibitor SP600125 enhances TGF- $\beta$ induced apoptosis of RBE human cholangiocarcinoma cells in a Smad-dependent manner. Mol Med Rep 2013;8:1623-9.

68. Li JY, Huang JY, Xing B, et al. SP600125, a JNK inhibitor, suppresses growth of JNKinactive glioblastoma cells through cellcycle G2/M phase arrest. Pharmazie 2012;67:942-6.

69. Jemaà M, Vitale I, Kepp 0 , et al. Selective killing of p53-deficient cancer cells by SP600125. EMBO Mol Med 2012;4:500-14.

70. Lu YY, Chen TS, Wang XP, et al. The JNK inhibitor SP600125 enhances dihydroartemisinin-induced apoptosis by accelerating Bax translocation into mitochondria in human lung adenocarcinoma cells. FEBS Lett 2010;584:4019-26.

71. Kim JH, Kim TH, Kang HS, et al. SP600125, an inhibitor of Jnk pathway, reduces viability of relatively resistant cancer cells to doxorubicin. Biochem Biophys Res Commun 2009;387:450-5.

72. Minutoli L, Altavilla D, Marini H, et al. Protective effects of SP600125 a new inhibitor of $\mathrm{c}$-jun $\mathrm{N}$-terminal kinase (JNK) and extracellular-regulated kinase (ERK1/2) in an experimental model of cerulein-induced pancreatitis. Life Sci 2004;75:2853-66.

73. $\mathrm{Hu}$ YB, Liu XY. Protective effects of SP600125 in a diet-induced rat model of non-alcoholic steatohepatitis. Scand J Gastroenterol 2009;44:1356-62.

74. Nath P, Eynott P, Leung SY, et al. Potential role of c-Jun NH2-terminal kinase in allergic airway inflammation and remodelling: effects of SP600125. Eur J
Pharmacol 2005;506:273-83.

75. Wu HM, Fang L, Shen QY, et al. SP600125 promotes resolution of allergic airway inflammation via TLR9 in an OVAinduced murine acute asthma model. Mol Immunol 2015;67:311-6.

76. Xu YF, Liu M, Peng B, et al. Protective effects of SP600125 on renal ischemiareperfusion injury in rats. $\mathrm{J}$ Surg Res 2011;169:e77-84

77. Wang Y, Ji HX, Xing SH, et al. SP600125, a selective JNK inhibitor, protects ischemic renal injury via suppressing the extrinsic pathways of apoptosis. Life Sci 2007;80:2067-75.

78. Takamura M, Matsuda Y, Yamagiwa S, et al. An inhibitor of c-Jun NH2-terminal kinase, SP600125, protects mice from D-galactosamine/lipopolysaccharide-induced hepatic failure by modulating BH3-only proteins. Life Sci 2007;80:1335-44.

79. Tabata A, Morikawa M, Miyajima M, et al. Suppression of alloreactivity and allograft rejection by SP600125, a small molecule inhibitor of c-Jun N-terminal kinase. Transplantation 2007;83:1358-64

80. De SK, Stebbins JL, Chen LH, et al. Design, synthesis, and structure-activity relationship of substrate competitive, selective, and in vivo active triazole and thiadiazole inhibitors of the c-Jun $\mathrm{N}$-terminal kinase. $\mathrm{J}$ Med Chem 2009;52:1943-52.

81. Augustine C, Cepinskas G, Fraser DD; Canadian Critical Care Translational Biology Group. Traumatic injury elicits JNK-mediated human astrocyte retraction in vitro. Neuroscience 2014;274:1-10.

82. Jang S, Javadov S. Inhibition of JNK aggravates the recovery of rat hearts after global ischemia: the role of mitochondrial JNK. PLoS One 2014;9:e113526.

83. Jang S, Yu LR, Abdelmegeed MA, et al. Critical role of c-jun $\mathrm{N}$-terminal protein kinase in promoting mitochondrial dysfunction and acute liver injury. Redox Biol 2015;6:552-64.

84. Plantevin Krenitsky V, Nadolny L, Delgado M, et al. Discovery of CC-930, an orally active anti-fibrotic JNK inhibitor. Bioorg Med Chem Lett 2012;22:1433-8.

85. Reich N, Tomcik M, Zerr P, et al. Jun Nterminal kinase as a potential molecular target for prevention and treatment of dermal fibrosis. Ann Rheum Dis 2012;71:737-45.

86. ClinicalTrials.gov. Trial Identifier NCT0120394. Available from: http://www. clinicaltrials.gov

87. Bogoyevitch MA, Arthur PG. Inhibitors of c-Jun N-terminal kinases: JuNK no more? Biochim Biophys Acta 2008;1784:76-93.

88. Wang J, Van De Water TR, Bonny C, et al. A peptide inhibitor of $\mathrm{c}$-Jun $\mathrm{N}$-terminal kinase protects against both aminoglyco- side and acoustic trauma-induced auditory hair cell death and hearing loss. J Neurosci 2003;23:8596-607.

89. Eshraghi AA, He J, Mou CH, Polak M, et al. D-JNKI-1 treatment prevents the progression of hearing loss in a model of cochlear implantation trauma. Otol Neurotol 2006;27:504-11.

90. Coleman JK, Littlesunday C, Jackson R, et al. AM-111 protects against permanent hearing loss from impulse noise trauma. Hear Res 2007;226:70-8.

91. Barkdull GC, Hondarrague Y, Meyer T, et al. AM-111 reduces hearing loss in a guinea pig model of acute labyrinthitis. Laryngoscope. 2007;117:2174-82.

92. Suckfuell M, Canis M, Strieth S, et al. Intratympanic treatment of acute acoustic trauma with a cell-permeable JNK ligand: a prospective randomized phase I/II study. Acta Otolaryngol 2007;127:938-42.

93. Suckfuell M, Lisowska G, Domka W et al. Efficacy and safety of AM-111 in the treatment of acute sensorineural hearing loss: a double-blind, randomized, placebo-controlled phase II study. Otol Neurotol 2014;35:1317-26.

94. Auris Medical. AM-111 for the treatment of acute inner ear hearing loss. Available from: http://www.aurismedical.com/product-candidates/am-111

95. El Zaoui I, Touchard E, Berdugo M, et al. Subconjunctival injection of XG-102, a cJun N-terminal kinase inhibitor peptide, in the treatment of endotoxin-induced uveitis in rats. $\mathrm{J}$ Ocul Pharmacol Ther 2015;31:17-24.

96. Beydoun T, Deloche C, Perino J, et al. Subconjunctival injection of XG-102, a JNK inhibitor peptide, in patients with intraocular inflammation: a safety and tolerability study. J Ocul Pharmacol Ther 2015;31:93-9.

97. Hirt L, Badaut J, Thevenet J, et al. DJNKI1, a cell-penetrating c-Jun-N-terminal kinase inhibitor, protects against cell death in severe cerebral ischemia. Stroke 2004;35:1738-43

98. Ginet V, Puyal J, Magnin G, et al. Limited role of the c-Jun N-terminal kinase pathway in a neonatal rat model of cerebral hypoxia-ischemia. J Neurochem 2009; 108:552-62.

99. Gao YJ, Cheng JK, Zeng Q, et al. Selective inhibition of JNK with a peptide inhibitor attenuates pain hypersensitivity and tumor growth in a mouse skin cancer pain model. Exp Neurol 2009;219:146-55.

100. Nijboer CH, Bonestroo HJ, Zijlstra J, et al. Mitochondrial JNK phosphorylation as a novel therapeutic target to inhibit neuroinflammation and apoptosis after neonatal ischemic brain damage. Neurobiol Dis 2013;54:432-44. 
101. Zhuang ZY, Wen YR, Zhang DR, et al. A peptide c-Jun $\mathrm{N}$-terminal kinase (JNK) inhibitor blocks mechanical allodynia after spinal nerve ligation: respective roles of JNK activation in primary sensory neurons and spinal astrocytes for neuropathic pain development and maintenance. J Neurosci 2006;26:3551-60.

102. Milano G, Morel S, Bonny C, et al. A peptide inhibitor of c-Jun NH2-terminal kinase reduces myocardial ischemiareperfusion injury and infarct size in vivo. Am J Physiol Heart Circ Physiol 2007;292:H1828-35.

103. Lehnert M, Relja B, Sun-Young Lee V, et al. A peptide inhibitor of $\mathrm{C}$-jun $\mathrm{N}$-terminal kinase modulates hepatic damage and the inflammatory response after hemorrhagic shock and resuscitation. Shock 2008;30:159-65.

104. Relja B, Schwestka B, Lee VS, et al. Inhibition of c-Jun N-terminal kinase after hemorrhage but before resuscita- tion mitigates hepatic damage and inflammatory response in male rats. Shock 2009;32:509-16.

105. Wiegler K, Bonny C, Coquoz D, et al. The JNK inhibitor XG-102 protects from ischemic damage with delayed intravenous administration also in the presence of recombinant tissue plasminogen activator. Cerebrovasc Dis 2008;26:360-6.

106. Ploia C, Antoniou X, Sclip A, et al. JNK plays a key role in tau hyperphosphorylation in Alzheimer's disease models. J Alzheimers Dis 2011;26:315-29.

107. Sclip A, Tozzi A, Abaza A, et al. c-Jun Nterminal kinase has a key role in Alzheimer disease synaptic dysfunction in vivo. Cell Death Dis 2014;5:e1019.

108. Hu Y, Peng N, Lei D, et al. [Impact of JNK inhibitor XG-102 in a diet-induced rat model of non-alcoholic steatohepatitis]. Zhonghua Gan Zang Bing Za Zhi 2014;22:948-52.

109. Reinecke K, Eminel S, Dierck F, et al. The
JNK inhibitor XG-102 protects against TNBS-induced colitis. PLoS One 2012;7:e30985.

110. Repici M, Chen X, Morel MP, et al. Specific inhibition of the JNK pathway promotes locomotor recovery and neuroprotection after mouse spinal cord injury. Neurobiol Dis 2012;46:710-21.

111. Bogoyevitch MA. The isoform-specific functions of the c-Jun $\mathrm{N}$-terminal Kinases (JNKs): differences revealed by gene targeting. Bioessays 2006;28:923-34.

112. Makhuri FR, Ghasemi JB. Computeraided scaffold hopping to identify a novel series of casein kinase 1 delta (CK1d) inhibitors for amyotrophic lateral sclerosis. Eur J Pharm Sci 2015;78:151-62.

113. Cicenas J, Kalyan K, Sorokinas A, et al. Highlights of the Latest Advances in Research on CDK Inhibitors. Cancers (Basel) 2014;6:2224-42. 